\title{
Atributos químicos, estoque de carbono orgânico total e das frações humificadas da matéria orgânica do solo em diferentes sistemas de manejo de cana-de-açúcar ${ }^{1}$
}

\author{
Chemical attributes, total organic carbon stock and humified \\ fractions of organic matter soil submitted to different systems of \\ sugarcane management
}

\author{
Jean Sérgio Rosset ${ }^{2 *}$; Jolimar Antonio Schiavo ${ }^{3}$; \\ Ricardo Augusto Rezende Atanázio ${ }^{4}$
}

\begin{abstract}
Resumo
A colheita mecanizada com manutenção do palhiço da cana-de-açúcar e a aplicação no solo de resíduos como vinhaça e torta de filtro podem promover melhorias no sistema produtivo da cultura. Assim, este trabalho objetivou avaliar as alterações nos atributos químicos, no estoque de carbono orgânico total e das frações humificadas da matéria orgânica de um Latossolo Vermelho cultivado com cana-de-açúcar com os seguintes sistemas de manejo: cana crua com aplicação de vinhaça (CCV), cana queimada sem aplicação de resíduos (CQS), cana queimada com aplicação de vinhaça (CQV), cana queimada com aplicação de torta de filtro (CQTF) e cana queimada com aplicação conjunta de vinhaça e torta de filtro (CQVTF). Como referência utilizou-se uma área de vegetação natural (VN), Cerrado sensu stricto. O tratamento CQVTF apresentou melhoria nos atributos químicos do solo, aumentou os estoques de carbono orgânico total - COT (valores variando de 21,28 a 40,02 $\mathrm{Mg} \mathrm{ha}^{-1}$ ) e das frações humificadas da matéria orgânica do solo em relação aos demais tratamentos. A área com CQS, na profundidade de $0-0,05 \mathrm{~m}$, apresentou as maiores perdas de estoques de COT do solo $(56,3 \%)$ em relação à $\mathrm{VN}$. A adoção do manejo CCV apresentou atributos químicos e estoques de COT do solo equivalentes aos observados nas áreas com CQV e CQTF apesar do curto período de adoção (3 anos). Os teores de COT correlacionaram-se com a soma de bases $\left(r=0,76^{* *}\right)$, capacidade de troca catiônica $\left(r=0,59^{* *}\right)$ e saturação por bases $\left(\mathrm{r}=0,63^{* *}\right)$; enquanto os ácidos húmicos $\left(\mathrm{r}=0,40^{* *}\right)$, fúlvicos $\left(\mathrm{r}=0,49^{* *}\right)$ e humina $\left(\mathrm{r}=0,59^{* *}\right)$ correlacionaram-se com a capacidade de troca catiônica do solo. Estes resultados indicam que a preservação do palhiço no manejo da cana-de-açúcar, somado à aplicação da torta de filtro e vinhaça aumentam os estoques de COT promovendo melhoria nos atributos químicos do solo.
\end{abstract}

Palavras-chave: Palhiço, vinhaça, torta de filtro, substâncias húmicas

\begin{abstract}
Mechanized harvesting maintenance of trash from cane sugar and soil application of waste as vinasse and filter cake can improve the system of crop yield. Thus, this study aimed to evaluate the changes in the chemical, the stock of total organic carbon and humified organic matter fractions in an Oxisol cultivated with cane sugar with the following management systems: with sugarcane vinasse application (CCV), without application of burnt cane waste (CQS), with burnt cane vinasse application (CQV),

Parte da Dissertação de Mestrado do primeiro autor, Universidade Estadual de Mato Grosso do Sul, UEMS, Aquidauana, MS.

Prof., Instituto Federal do Paraná, IFPR, Assis Chateaubriand, PR. E-mail: jean.rosset@ifpr.edu.br

Prof., Adjunto IV, UEMS, Aquidauana, MS. E-mail: schiavo@uems.br

${ }^{4}$ Eng $^{\text {o }}$ Agr $^{\circ}$, UEMS, Aquidauana, MS. E-mail: ricardo_augusto01@hotmail.com
\end{abstract}

* Autor para correspondência 
with application of burnt cane filter cake (CQTF) and burnt cane with joint application of vinasse and filter cake (CQVTF). For reference we used an area of natural vegetation (NV), Cerrado sensu stricto. Treatment CQVTF showed improvement in soil chemical properties, increased inventory levels of total organic carbon - TOC (values ranging from 21.28 to $40.02 \mathrm{Mg} \mathrm{ha}^{-1}$ ) and humified fractions of soil organic matter in relation to other treatments. The CQS area at a depth of 0-0.05 m, showed the greatest losses of soil TOC stocks (56.3\%) compared to NV. The adoption of management presented CCV and chemical attributes of the soil TOC stocks equivalent to those observed in areas with CQV CQTF and despite the short period of adoption ( 3 years). The TOC correlated with the sum of bases $(\mathrm{r}=0.76 * *)$, cation exchange capacity $\left(\mathrm{r}=0.59^{* *}\right)$ and base saturation $(\mathrm{r}=0.63 * *)$, while the humic acids $(\mathrm{r}=0.40$ **) fulvic acids $(\mathrm{r}=0.49 * *)$ and humin $(\mathrm{r}=0.59 * *)$ correlated with the cation exchange capacity of the soil. These results indicate that the preservation of trash in the management of cane sugar, added to the application of vinasse and filter cake increases the TOC stocks promoting improvement in soil chemical properties.

Key words: Straw, vinasse, filter cake, humic substances

\section{Introdução}

Em virtude do aumento da demanda pelo açúcar e etanol combustível, a área de plantio da canade-açúcar continua se expandindo no Brasil, com frequente aumento de produtividade. $\mathrm{O}$ cenário econômico atual indica um mercado favorável, estimulando a expansão das áreas plantadas, muitas vezes substituindo outras culturas e pastagens ou em áreas de vegetação nativa de Cerrado (GALDOS et al., 2009; OLIVEIRA; FERREIRA; ARAÚJO, 2012). Especificamente, o estado de Mato Grosso do Sul está entre os cinco maiores produtores de cana-de-açúcar do país com área plantada na safra 2013/14 de 624 mil hectares, estimando-se uma produção de 43,9 milhões de toneladas, sendo 15,9 milhões de toneladas destinadas à produção de açúcar e 28 milhões de toneladas para a produção de etanol, com produtividade estimada de $70.300 \mathrm{~kg}$ ha $^{-1}$ (CONAB, 2013).

Com a expansão da área de plantio de canade-açúcar, além do incremento no número de usinas, têm-se o aumento na produção de resíduos da indústria sucroalcooleira como a vinhaça e a torta de filtro. Estes resíduos quando aplicados na agricultura como fonte de nutrientes, reduz a contaminação ambiental e os custos com adubação, proporcionando maior rentabilidade tanto para o setor econômico quanto ao ambiental da cadeira produtiva do etanol da cana-de-açúcar (FRAVET et al., 2010). A torta de filtro quando aplicada na lavoura proporciona incremento nos teores de fósforo e atua como condicionador das propriedades físicas do solo (SANTOS et al., 2011). Já a aplicação da vinhaça é motivada pelos seus elevados teores de potássio, cálcio e magnésio (BEBÉ et al., 2009).

A manutenção do palhiço da cana-de-açúcar sobre o solo, bem como a aplicação dos resíduos da indústria sucroalcooleira como a torta de filtro e vinhaça, promove aumento nos teores de matéria orgânica do solo (MOS) (CANELLAS et al., 2003), componente fundamental para a manutenção da qualidade do solo, estando envolvida em diversos processos físicos, químicos e biológicos (LEITE et al., 2003; ROSCOE; BODDEY; SALTON, 2006).

Dentre os atributos que podem ser utilizados para avaliar a sustentabilidade dos sistemas agrícolas tem-se o conteúdo e a qualidade da matéria orgânica (MIELNICZUK, 1999). Grande parte da MOS consiste de uma série de compostos ácidos não-humificados e macromoléculas humificadas (GUERRA et al., 2008). A formação de substâncias húmicas é caracterizada por um processo complexo baseado na síntese e, ou, ressíntese dos produtos da mineralização dos compostos orgânicos que chegam ao solo (CAMARGO; SANTOS; GUERRA, 1999). Vários estudos enfatizam a importância da quantificação do carbono nas diferentes frações da MOS, devido ao interesse de se conhecer o potencial de captura e armazenamento do carbono nos diferentes sistemas de uso do solo, reduzindo 
assim o impacto da agricultura sobre o ambiente (GREGORICH et al., 2006). Solos com maior conteúdo de MOS estável contribuem de maneira significativa para a redução das taxas de emissão de $\mathrm{CO}_{2}$ para a atmosfera (KRAGT et al., 2012), pois a proporção destas frações indicam o grau de humificação/estabilização da MOS (CANELLAS et al., 2003).

Solos de textura argilosa, como os Latossolos da região central do Brasil, possuem alta resiliência, ou seja, capacidade de se recuperar de algum tipo de degradação, ao qual foi submetido e, retornar a um novo equilíbrio, especialmente com relação ao estoque de carbono orgânico, devido principalmente aos altos teores de óxidos e hidróxidos de ferro e alumínio que, juntamente com o tipo de estrutura desses solos, auxiliam na proteção da MOS (RESCK et al., 2008). Schiavo et al. (2011) observaram aumento nos teores de carbono orgânico total e das frações humificadas da matéria orgânica em solos de Cerrado manejados integrando lavoura pecuária sob plantio direto; proporcionando melhoria na agregação do solo e no índice de manejo de carbono.

Neste contexto, o objetivo do presente trabalho foi avaliar as alterações nos atributos químicos, no estoque de carbono orgânico total e das frações humificadas da matéria orgânica de um Latossolo Vermelho cultivado com cana-de-açúcar sob diferentes manejos de colheita e aplicação de resíduos da indústria sucroalcooleira.

\section{Material e Métodos}

O presente estudo foi realizado na Usina LDCSEV, localizada no município de Maracaju, MS. O município é definido geograficamente pelas coordenadas $21^{\circ} 37^{\prime}$ de latitude sul e $55^{\circ} 08^{\prime}$ de longitude oeste, com altitude de aproximadamente 400 metros. O clima da região, segundo classificação de Köppen, pertence ao tipo Aw (tropical úmido), com precipitação média anual de $1.200 \mathrm{~mm}$; temperaturas máximas e mínimas de $33{ }^{\circ} \mathrm{C}$ e $19,6{ }^{\circ} \mathrm{C}$, respectivamente. $\mathrm{O}$ solo das áreas amostradas foi classificado como Latossolo Vermelho (EMBRAPA, 2013), com textura argilosa cujos teores de argila variaram de 537 a $650 \mathrm{~g} \mathrm{~kg}^{-1}$ na profundidade de $0,2 \mathrm{~m}$ (Tabela 1 ).

Os tratamentos com cana-de-açúcar correspondem ao manejo da queima e não queima do canavial antes da colheita mecanizada, e aplicação de resíduos da indústria sucroalcooleira, como descritos: 1) colheita sem queima por três anos consecutivos associada à aplicação de vinhaça (cana crua) - CCV. 2) queima do canavial sem aplicação de resíduos - CQS. 3) queima com aplicação de vinhaça durante 16 anos consecutivos - CQV. 4) queima com aplicação de torta de filtro - CQTF. 5) queima com aplicação de vinhaça mais torta de filtro - CQVTF. A vinhaça foi aplicada em toda a superfície enquanto a torta de filtro nas entre linhas de cultivo da cana-de-açúcar. Como referência foi utilizada uma área de vegetação nativa (VN), Cerrado sensu stricto.

Em todas as áreas, a reforma do canavial é feita com arado de discos e aplicação de 3 e $2 \mathrm{t} \mathrm{ha}^{-1}$ de calcário e gesso, respectivamente. A vinhaça aplicada no canavial apresentou 0,13, 0,01, 0,64, 0,28, 0,12 e 0,33 $\mathrm{g} \mathrm{L}^{-1}$ de $\mathrm{N}, \mathrm{P}, \mathrm{K}, \mathrm{Ca}, \mathrm{Mg}$ e $\mathrm{S}$, respectivamente; e 18,80, 0,20, 9,20, 0,20 e 4,20 mg $\mathrm{L}^{-1}$ de $\mathrm{Na}, \mathrm{Cu}, \mathrm{Fe}, \mathrm{Zn}$ e $\mathrm{Mn}$, respectivamente. Já a torta de filtro apresentou 11,90, 10,00, 4,10, 17,75, 3,23, 6, $00 \mathrm{~g} \mathrm{~kg}^{-1}$ de N, P, Ca, Mg, S respectivamente; e 180, 130, 36, 133, 710 e $70 \mathrm{mg} \mathrm{kg}^{-1}$ de $\mathrm{Na}, \mathrm{Cu}, \mathrm{Fe}$, $\mathrm{Zn}$ e $\mathrm{Mn}$ respectivamente.

A coleta de solo foi realizada em três profundidades $(0-0,05,0,05-0,1$ e 0,1-0,2 m), em três amostras compostas formadas por dez amostras simples em área de $400 \mathrm{~m}^{2}$. Após a coleta, as amostras foram secas ao ar, destorroadas e passadas em peneira de $2 \mathrm{~mm}$ obtendo-se a terra fina seca ao ar (TFSA). 
Tabela 1. Granulometria e densidade do solo (Ds) em função dos sistemas de manejo de colheita e aplicação de resíduos da indústria sucroalcooleira em área cultivada com cana-de-açúcar.

\begin{tabular}{|c|c|c|c|c|}
\hline \multirow{2}{*}{ Manejo da cultura } & Areia & Silte & Argila & Ds \\
\hline & \multicolumn{3}{|c|}{----------g kg k'------- } & $\mathrm{g} \mathrm{cm}^{-3}$ \\
\hline & \multicolumn{4}{|c|}{$0-0,05 \mathrm{~m}$} \\
\hline $\mathrm{CCV}$ & 167 & 285 & 548 & $1,53 \mathrm{a}$ \\
\hline CQS & 219 & 219 & 562 & $1,34 b$ \\
\hline CQV & 143 & 259 & 598 & $1,32 b$ \\
\hline CQTF & 246 & 169 & 585 & $1,55 \mathrm{a}$ \\
\hline CQVTF & 188 & 245 & 567 & $1,50 \mathrm{a}$ \\
\hline VN & 176 & 266 & 558 & $0,89 \mathrm{c}$ \\
\hline \multirow[t]{2}{*}{$\mathrm{CV}(\%)$} & & & & 6,76 \\
\hline & \multicolumn{4}{|c|}{$0,05-0,1 \mathrm{~m}$} \\
\hline $\mathrm{CCV}$ & 150 & 289 & 561 & $1,49 \mathrm{a}$ \\
\hline CQS & 213 & 244 & 543 & $1,43 b$ \\
\hline CQV & 132 & 251 & 617 & $1,35 b$ \\
\hline CQTF & 243 & 150 & 607 & $1,57 \mathrm{a}$ \\
\hline CQVTF & 183 & 217 & 600 & $1,56 \mathrm{a}$ \\
\hline VN & 190 & 195 & 615 & $1,03 c$ \\
\hline \multirow[t]{2}{*}{ CV (\%) } & & & & 4,75 \\
\hline & \multicolumn{4}{|c|}{$0,1-0,2 \mathrm{~m}$} \\
\hline $\mathrm{CCV}$ & 161 & 302 & 537 & $1,49 b$ \\
\hline CQS & 206 & 236 & 558 & $1,44 b$ \\
\hline $\mathrm{CQV}$ & 126 & 249 & 625 & $1,39 b$ \\
\hline CQTF & 250 & 152 & 598 & $1,58 \mathrm{a}$ \\
\hline CQVTF & 177 & 213 & 610 & $1,53 \mathrm{a}$ \\
\hline $\mathrm{VN}$ & 181 & 169 & 650 & $1,10 \mathrm{c}$ \\
\hline CV (\%) & & & & 4,20 \\
\hline
\end{tabular}

Médias seguidas de letras iguais, na coluna, em cada profundidade, não diferem entre si pelo teste de Scott-Knott a $5 \%$ de probabilidade. CCV: cana crua com aplicação de vinhaça. CQS: cana queimada sem aplicação de resíduos. CQV: cana queimada com aplicação de vinhaça. CQTF: cana queimada com aplicação de torta de filtro. CQVTF: cana queimada com aplicação de vinhaça e torta de filtro. VN: vegetação natural.

Fonte: Elaboração dos autores.

As análises físicas e químicas foram efetuadas segundo metodologia descrita por Embrapa (1997). A densidade do solo foi determinada em amostras indeformadas coletadas com auxílio de anel volumétrico $\left(72,38 \mathrm{~cm}^{3}\right)$, e a análise granulométrica pelo método da pipeta. $\mathrm{O} \mathrm{pH}$ foi determinado em água (relação solo: solução 1:2,5); $\mathrm{Ca}^{2+} \mathrm{e} \mathrm{Mg}^{2+}$ trocáveis (extraídos com $\mathrm{KCl} 1 \mathrm{~mol}$ $\mathrm{L}^{-1}$ e determinados por complexiometria), $\mathrm{Na}^{+}$e $\mathrm{K}^{+}$ trocáveis (extraídos por solução de $\mathrm{HCl} 0,05 \mathrm{~mol}$ $\mathrm{L}^{-1}$ e determinados por fotometria de chama), $\mathrm{Al}^{3+}$ trocável (extraído com solução de $\mathrm{KCl} 1 \mathrm{~mol} \mathrm{~L}^{-1} \mathrm{e}$ determinado por titulação), $\mathrm{H}^{+}+\mathrm{Al}^{3+}$ (extraídos com solução de acetato de cálcio $0,5 \mathrm{~mol} \mathrm{~L}^{-1}$ tamponado a pH 7,0 e determinados por titulação), P disponível, extraído com solução Mehlich-1 e determinado por colorimetria. Com base nos resultados das análises químicas, foram calculados os valores da soma de bases (SB), a capacidade de troca catiônica (CTC) e a saturação por bases (V) (EMBRAPA, 1997). O carbono orgânico total (COT) foi determinado pela oxidação da matéria orgânica pelo dicromato de potássio, em meio sulfúrico, e titulado com sulfato ferroso amoniacal (YEOMANS; BREMNER, 1988).

O fracionamento químico da matéria orgânica foi realizado a partir da simplificação do método de 
Benites, Mádari e Machado (2003), com base nas características de solubilidade diferencial. Foram pesados 1,0 g de TFSA, em seguida colocou-se uma mistura extratora de $\mathrm{NaOH} 0,1 \mathrm{~mol} \mathrm{~L}^{-1}$, onde as frações ácido fúlvico (AF) e ácido húmico (AH) solubilizaram. A humina (HU) foi o resíduo sólido insolúvel resultante do processo de fracionamento. Os AH foram separados dos AF por centrifugação após precipitação em meio ácido obtido com adição $\mathrm{de}_{2} \mathrm{SO}_{4} 20 \%$ até valor de $\mathrm{pH} 1$. Em seguida, após lavagens, os $\mathrm{AH}$ foram redissolvidos em $\mathrm{NaOH} 0,1$ mol L-1. A quantificação do carbono orgânico nas frações $\mathrm{AF}$ e $\mathrm{AH}$ foi feita usando-se alíquotas de 5,0 $\mathrm{mL}$ de extrato, $1,0 \mathrm{~mL}$ de dicromato de potássio 0,042 $\mathrm{mol} \mathrm{L}^{-1}$ e 5,0 $\mathrm{mL}$ de $\mathrm{H}_{2} \mathrm{SO}_{4}$ concentrado, em bloco digestor a $150{ }^{\circ} \mathrm{C}$ e titulação com sulfato ferroso amoniacal $0,0125 \mathrm{~mol} \mathrm{~L}^{-1}$. No resíduo seco em estufa, foi determinado o carbono orgânico da fração $\mathrm{HU}$, adicionando-se 5,0 $\mathrm{mL}$ de dicromato de potássio 0,1667 $\mathrm{mol} \mathrm{L}^{-1}$ e $10,0 \mathrm{ml}$ de $\mathrm{H}_{2} \mathrm{SO}_{4}$ concentrado, em bloco digestor a $150{ }^{\circ} \mathrm{C}$ e titulação com sulfato ferroso amoniacal $0,25 \mathrm{~mol} \mathrm{~L}^{-1}$.

Os estoques de COT do solo e das frações humificadas da matéria orgânica foram calculados empregando-se a equação: $\mathrm{EstC}=(\mathrm{C} \times \mathrm{Ds} \times \mathrm{p}) / 10$, em que EstC $=$ estoque de carbono do solo $\left(\mathrm{Mg}^{-}\right.$ $\left.{ }^{1}\right) ; \mathrm{C}=$ teor de carbono $\left(\mathrm{g} \mathrm{kg}^{-1}\right)$; Ds = densidade do solo $\left(\mathrm{g} \mathrm{cm}^{-3}\right)$; e $\mathrm{p}=$ profundidade da camada do solo (cm).

Para verificar o acúmulo ou a perda de carbono orgânico, foi calculada a variação do estoque de COT e das frações humificadas em relação à área de mata nativa $\left(\triangle \mathrm{EstC}, \mathrm{Mg} \mathrm{ha} \mathrm{cm}^{-1}\right)$, pela diferença entre os valores médios de estoque de carbono orgânico neste sistema e em cada um dos demais, dividida pela espessura $(\mathrm{cm})$ da camada de solo avaliada.

Os dados foram avaliados segundo delineamento inteiramente casualizado, onde os sistemas de manejo de cana-de-açúcar e a área de Cerrado nativo foram considerados os tratamentos. Após análise de variância, quando significativa, a comparação das médias foi efetuada pelo teste de Skott-Knott a $5 \%$ de probabilidade. Adicionalmente foi realizada análise de correlação de Pearson entre os atributos químicos e os teores de COT e carbono das frações humificadas.

\section{Resultados e Discussão}

Os maiores valores de Ds ocorreram nas áreas manejadas com CCV, CQTF e CQVTF, principalmente nas profundidades de 0-0,05 e 0,050,1 m (Tabela 1). Para a profundidade de 0,1-0,2 $\mathrm{m}$ as áreas que receberam apenas aplicação de torta de filtro apresentaram valores superiores para esta variável. Esses maiores valores de Ds possivelmente estão associados à maior compactação do solo pelo uso de máquinas colhedoras nestas áreas. Entretanto, os menores valores de Ds foram observados na área com VN, variando de 0,89 a $1,10 \mathrm{~g} \mathrm{~cm}^{-3}$ para todas as profundidades avaliadas. Este resultado pode ser atribuído por ser uma área de vegetação preservada com baixa influência antrópica, diferentemente das áreas manejadas com cana-de-açúcar que passam por um preparo intensivo de condicionamento do solo. Lemos Filho et al. (2008) estudando a variação espacial da densidade do solo cultivado com canade-açúcar utilizando técnicas da geoestatística, verificaram menores valores na camada superficial de $0-0,2 \mathrm{~m}$, tendo correlação com os maiores teores de carbono orgânico.

As práticas de manejo de colheita e aplicação de resíduos na cultura da cana-de-açúcar promoveram alterações nos atributos químicos do solo (Tabela 2). Os maiores valores de $\mathrm{pH}$ ocorreram sob manejo com CQS, variando de 6,43 a 6,74 nas profundidades de 0-0,05 e 0,05-0,1 m, respectivamente, semelhantes aos da VN. A elevação do $\mathrm{pH}$ do solo após a queima de resíduos vegetais, deve-se ao efeito das cinzas, que reduzem temporariamente os teores de Al (COUTINHO, 1994) e de ácidos orgânicos e, ao mesmo tempo, aumentam a saturação de bases na superfície do solo (SCHACHT et al., 1996). A queima também afeta a estacionalidade e forma 
disponível de alguns elementos minerais no solo (HERINGER et al., 2002).

No solo sob VN em todas as profundidades, observaram-se os maiores teores de COT em relação às áreas manejadas com cana-de-açúcar (Tabela 2); sendo estes relacionados ao aporte constante de resíduos vegetais sobre a superfície do solo, bem como a não perturbação do sistema; diferentemente das áreas manejadas, onde há mobilização do solo no momento da reforma do canavial aumentando a exposição do carbono ao ataque microbiano e efeitos erosivos, além da prática da queima que precede a colheita, contribuindo para a perda de carbono orgânico do solo na forma de $\mathrm{CO}_{2}$ para a atmosfera (CEDDIA et al., 1999; MENDONZA et al., 2000).

As perdas de COT ocorrem na ordem de 66, 71, 51, 67 e $44 \%$ nas áreas de CCV, CQS, CQV, CQTF e CQVTF, respectivamente, em comparação com a VN. Dentre as áreas manejadas com cana-deaçúcar, aquela com CQVTF apresentou os maiores teores de COT, principalmente nas profundidades de 0,05-0,1 e 0,1-0,2 m, sendo semelhantes aos da VN; sugerindo, que a perda da matéria orgânica do solo em alguns sistemas de cultivo pode ser compensada com a aplicação de resíduos (MARRIOTT; WANDER, 2006), com grande contribuição da vinhaça, como também relatado nos trabalhos de Canellas et al. (2003) em um Cambissolo cultivado com cana-de-açúcar com 35 anos de aplicação de vinhaça, Oliveira et al. (2010) com aplicações sucessivas por 25 anos e Vicente et al. (2012) com 12 anos de aplicação de vinhaça.
Comparando as áreas de queima e não queima + aplicação ou não de vinhaça (CCV e CQV), aquela cuja queima (CQV) antecedeu a colheita apresentou os maiores teores de COT, diferindo entre si na profundidade de 0-0,05 m $(28,29 \mathrm{~g} \mathrm{~kg}$ $\left.{ }^{1}\right)$. Isso se deve provavelmente, ao fato do maior tempo de aplicação de vinhaça nesta área (16 anos), diferentemente da área de colheita com cana crua, que passou a receber vinhaça somente após a conversão do sistema de colheita (3 anos). A velocidade da decomposição dos resíduos orgânicos varia de acordo com a resistência que ele oferece ao ataque microbiano, a vinhaça é rica em compostos oriundos da lise de células de leveduras e do mosto parcialmente fermentado, constituindo-se em material de fácil decomposição (GLÓRIA, 1980) o que pode favorecer os processos de estabilização do carbono no solo, com a formação de frações mais estáveis da MOS, como a humina (BARRETO et al., 2008).

A manutenção dos teores de MOS é indispensável para a qualidade do solo, sendo que uma das formas de aumentar seus teores é a preservação da palhada da cana-de-açúcar sobre sua superfície. Canellas et al. (2003) verificaram que o efeito da palhada sobre o solo possibilitou prolongar de 4 para 8 anos o cultivo sem renovação do canavial, em um experimento conduzido em áreas que a queimada foi extinta por 50 anos. Ainda, de acordo com Campos (2003), a adoção do sistema sem queima antes da colheita do canavial tornou positivo o balanço do $\mathrm{CO}_{2}$. O carbono que seria emitido através da queima da biomassa pôde permanecer no sistema e ser incorporado ao solo através da atividade microbiana, reduzindo assim o impacto ambiental. 


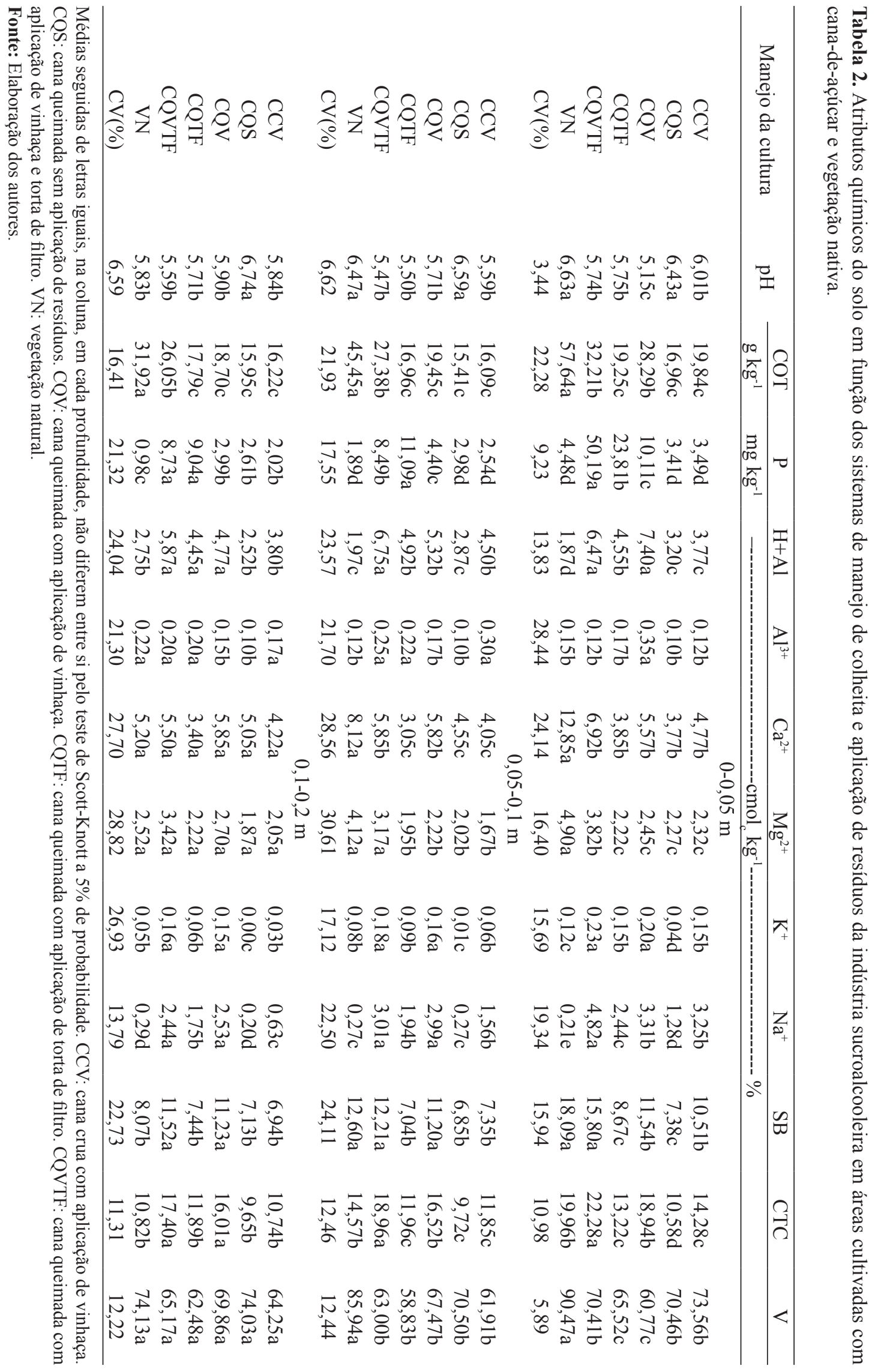


Em todas as áreas avaliadas, os teores de $\mathrm{P}$ diminuíram em profundidade (Tabela 2). Nas áreas manejadas com CQTF e CQVTF ocorreram os maiores teores diferindo estatisticamente das demais áreas estudadas em todas as profundidades, sendo os maiores teores encontrados na profundidade de 0-0,05 m 23,81 e 50,19 $\mathrm{mg} \mathrm{kg}^{-1}$, respectivamente, diferindo entre si para essa profundidade. Esse fato deve-se ao maior teor de $\mathrm{P}$ presente na torta de filtro. Quando se compara apenas as áreas que receberam vinhaça (CCV e CQV) observam-se maiores teores de $\mathrm{P}$ na área que recebeu vinhaça por maior período (CQV), diferindo-se estatisticamente para as duas primeiras profundidades. Aumentos nos teores de $\mathrm{P}$ do solo por aplicações sucessivas de vinhaça também foram relatados por Canellas et al. (2003); Busato, Canellas e Velloso (2005); Busato et al. (2005) e Ribeiro et al. (2011). Os maiores teores de $\mathrm{Al}$ trocável e $\mathrm{H}+\mathrm{Al}$ ocorreram na área de $\mathrm{CQV}$, especialmente na profundidade de 0-0,05 m, podendo estar relacionados ao menor valor de $\mathrm{pH}$ desta área. Menores valores de $\mathrm{pH}$ do solo tendem a deixar disponível o $\mathrm{Al}^{3+}$, podendo ser prejudicial a maioria das culturas (ABREU JUNIOR; MURAOKA; LAVORANTE, 2003).

Em todas as profundidades avaliadas, aquelas que receberam aplicação de vinhaça apresentaram os maiores teores de $\mathrm{Na}^{+}$e $\mathrm{K}^{+}$; fato este, justificado aos elevados teores destes elementos neste resíduo. Maia e Ribeiro (2004); Bebé et al. (2009) também encontraram maiores teores de $\mathrm{K}^{+}$em áreas com aplicação de vinhaça em cultivos de cana-de-açúcar. Altos teores de $\mathrm{Na}^{+}$presentes na vinhaça, devemse ao uso intensivo de soda cáustica nas operações industriais, fazendo com que este resíduo possa ser considerado potencialmente poluidor, em especial de águas subterrâneas quando aplicado de forma incorreta.

$\mathrm{O}$ solo sob $\mathrm{VN}$ apresentou os maiores teores das bases trocáveis $\mathrm{Ca}^{2+}$ e $\mathrm{Mg}^{2+}$, principalmente na profundidade de 0-0,05 m, seguido da área com CQVTF, devido principalmente aos maiores teores destes elementos presentes nestes resíduos. Para essas bases trocáveis, somente na profundidade de 0,1-0,2 m não houve diferença entre as áreas avaliadas. Segundo Motta et al. (2002), maiores

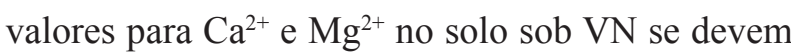
ao material de origem, rocha basáltica da região, e à ciclagem de nutrientes com acúmulo nas camadas superficiais. Os valores de SB variaram de 6,85 a $18,09 \mathrm{cmol}_{\mathrm{c}} \mathrm{kg}^{-1}$ (Tabela 2). Menores valores de SB nas áreas manejadas com cana-de-açúcar podem estar relacionados à redução da matéria orgânica nestes sistemas em relação ao solo sob VN.

Os maiores valores de CTC do solo ocorreram nas áreas com queima do canavial e aplicação de vinhaça, podendo estes ter relação com os elevados teores de $\mathrm{H}+\mathrm{Al}$ dessas áreas. A elevação da CTC ocorre pelo grande aporte de matéria orgânica representado pelas adições da vinhaça. Pela característica coloidal da matéria orgânica contida na vinhaça, sua adição confere ao solo uma maior quantidade de cargas negativas, diminuindo a lixiviação de cátions e aumentando consequentemente a CTC (GLÓRIA; ORLANDO FILHO, 1983). Maiores valores para CTC do solo também foram encontrados por Silva et al. (2006) em áreas de cana-de-açúcar que receberam aplicação de vinhaça por 25 anos consecutivos. Maia e Ribeiro (2004) observaram que o cultivo contínuo de canade-açúcar por 30 anos com aplicação de $350 \mathrm{~m}^{3} \mathrm{ha}^{-1}$ $\mathrm{ano}^{-1}$ de vinhaça, proporcionou redução nos teores de $\mathrm{Ca}^{2+}, \mathrm{Mg}^{2+}$, V, CTC e COT, e aumentou os teores de $\mathrm{P}$ e $\mathrm{Al}^{3+}$ em comparação ao solo sob vegetação natural.

Todas as áreas estudadas apresentaram valores de saturação por bases acima de $50 \%$, o que caracteriza o solo de caráter eutrófico, com destaque para a área de VN. De maneira geral, houve declínio na fertilidade do solo das áreas manejadas de cana-deaçúcar em relação à $\mathrm{VN}$, fato também demonstrado por Maia e Ribeiro (2004) e Silva et al. (2006), porém, as áreas que receberam a aplicação dos resíduos, a diminuição na fertilidade foi menos acentuada.

Os diferentes sistemas de manejo proporcionaram alterações nos estoques de COT e das frações 
humificadas da MOS (Tabela 3). Para todas as profundidades avaliadas, apenas a área de CQVTF apresentou estoque de COT semelhantes à área de VN com valores de 24,07, 21,28 e 40,02 $\mathrm{Mg} \mathrm{ha}^{-1}$ nas profundidades de 0-0,05, 0,05-0,1 e 0,1-0,2 m, respectivamente. Leite et al. (2003) relatam que a redução dos estoques de COT quando se faz a conversão de florestas nativas por sistemas agrícolas, pode ser atribuída ao aumento da erosão do solo, aos processos mais acelerados de mineralização da matéria orgânica e oxidação de COT e, às menores quantidades de aportes orgânicos em sistemas manejados comparativamente às florestas nativas, reduzindo assim, os estoques de COT dos solos cultivados.

Tabela 3. Estoque de carbono orgânico total (ECOT) e das frações humificadas da matéria orgânica do solo: humina (HU), ácido húmico $(\mathrm{AH})$ e ácido fúlvico (AF) e relação $\mathrm{AH} / \mathrm{AF}$ em função dos sistemas de manejo de colheita e aplicação de resíduos da indústria sucroalcooleira em área cultivada com cana-de-açúcar.

\begin{tabular}{|c|c|c|c|c|c|}
\hline Manejo da cultura & ECOT & $\mathrm{AH}$ & $\mathrm{AF}$ & $\mathrm{HU}$ & $\mathrm{AH} / \mathrm{AF}$ \\
\hline & \multicolumn{5}{|c|}{$\mathrm{Mg} \mathrm{ha}^{-1}$} \\
\hline & & & $0-0,05 \mathrm{~m}$ & & \\
\hline $\mathrm{CCV}$ & $15,23 b$ & $2,70 \mathrm{a}$ & $2,43 b$ & $9,11 b$ & 1,15 \\
\hline CQS & $11,29 b$ & $2,04 \mathrm{a}$ & $2,09 b$ & $7,43 b$ & 0,98 \\
\hline CQV & $18,69 b$ & $2,90 \mathrm{a}$ & $2,24 b$ & $10,66 b$ & 1,32 \\
\hline CQTF & $15,06 \mathrm{~b}$ & $2,79 a$ & $2,40 \mathrm{~b}$ & $8,79 b$ & 1,21 \\
\hline CQVTF & $24,07 \mathrm{a}$ & $2,84 \mathrm{a}$ & $3,95 \mathrm{a}$ & $14,52 \mathrm{a}$ & 0,72 \\
\hline VN & $25,79 a$ & $2,31 \mathrm{a}$ & $2,89 \mathrm{~b}$ & $14,39 a$ & 1,06 \\
\hline \multirow[t]{2}{*}{ CV $(\%)$} & 20,59 & 23,27 & 17,47 & 30,24 & \\
\hline & & & $0,05-0,1 \mathrm{~m}$ & & \\
\hline $\mathrm{CCV}$ & $11,99 b$ & $2,60 \mathrm{a}$ & $2,59 b$ & $6,02 \mathrm{a}$ & 1,01 \\
\hline CQS & $11,04 b$ & $1,91 \mathrm{a}$ & $2,26 b$ & $7,45 \mathrm{a}$ & 0,89 \\
\hline CQV & $13,18 b$ & $2,81 \mathrm{a}$ & $1,88 \mathrm{~b}$ & $9,43 a$ & 1,50 \\
\hline CQTF & $13,34 b$ & $2,97 \mathrm{a}$ & $2,20 \mathrm{~b}$ & $6,71 \mathrm{a}$ & 1,56 \\
\hline CQVTF & $21,28 \mathrm{a}$ & $3,16 \mathrm{a}$ & $4,26 a$ & $11,61 \mathrm{a}$ & 0,75 \\
\hline VN & $23,38 \mathrm{a}$ & $2,18 \mathrm{a}$ & $2,64 b$ & $8,91 \mathrm{a}$ & 0,84 \\
\hline \multirow[t]{2}{*}{ CV $(\%)$} & 20,23 & 22,78 & 23,36 & 30,14 & \\
\hline & & & $0,1-0,2 \mathrm{~m}$ & & \\
\hline $\mathrm{CCV}$ & $24,26 b$ & $4,42 \mathrm{a}$ & $4,44 b$ & $13,21 \mathrm{a}$ & 0,99 \\
\hline CQS & $22,96 b$ & $3,74 \mathrm{a}$ & $3,06 \mathrm{c}$ & $15,63 \mathrm{a}$ & 1,30 \\
\hline CQV & $25,58 b$ & $3,38 \mathrm{a}$ & $4,43 b$ & $19,55 \mathrm{a}$ & 0,74 \\
\hline CQTF & $28,38 b$ & $5,43 \mathrm{a}$ & $6,07 a$ & $13,62 \mathrm{a}$ & 0,89 \\
\hline CQVTF & $40,02 \mathrm{a}$ & $5,53 \mathrm{a}$ & $7,19 a$ & $20,13 a$ & 0,77 \\
\hline $\mathrm{VN}$ & $35,17 \mathrm{a}$ & $4,85 \mathrm{a}$ & $4,71 b$ & $15,18 \mathrm{a}$ & 1,06 \\
\hline CV (\%) & 19,10 & 26,96 & 15,29 & 24,91 & \\
\hline
\end{tabular}

Médias seguidas de letras iguais, na coluna, em cada profundidade, não diferem entre si pelo teste de Scott-Knott a 5\% de probabilidade. CCV: cana crua com aplicação de vinhaça. CQS: cana queimada sem aplicação de resíduos. CQV: cana queimada com aplicação de vinhaça. CQTF: cana queimada com aplicação de torta de filtro. CQVTF: cana queimada com aplicação de vinhaça e torta de filtro. VN: vegetação natural.

Fonte: Elaboração dos autores. 
Apesar da área com aplicação de torta mais vinhaça passar pelo processo de queima antes da colheita do canavial, a aplicação dos resíduos contribuiu para que a diminuição no estoque de COT do solo desta área não fosse tão acentuada em comparação com a VN (Figura 1A). Os estoques de COT em áreas cultivadas com cana-de-açúcar, entre outros fatores, são influenciados pela textura do solo e aplicação de fertilizantes minerais e orgânicos (GALDOS et al., 2009) como a aplicação de vinhaça e torta de filtro. Desta forma, áreas que recebem estes resíduos, aumentam seus estoques de carbono comparativamente às áreas que não recebem e, consequentemente, apresentam potencial de sequestro de carbono (RESCK et al., 2008).

Figura 1. Variação do estoque de carbono orgânico total (A) e da fração humina (B) em função dos sistemas de manejo de colheita e aplicação de resíduos da indústria sucroalcooleira em área cultivada com cana-de-açúcar, em relação à mata. $\mathrm{CCV}$ : cana crua com aplicação de vinhaça. CQS: cana queimada sem aplicação de resíduos. CQV: cana queimada com aplicação de vinhaça. CQTF: cana queimada com aplicação de torta de filtro. CQVTF: cana queimada com aplicação de vinhaça e torta de filtro. VN: vegetação natural.

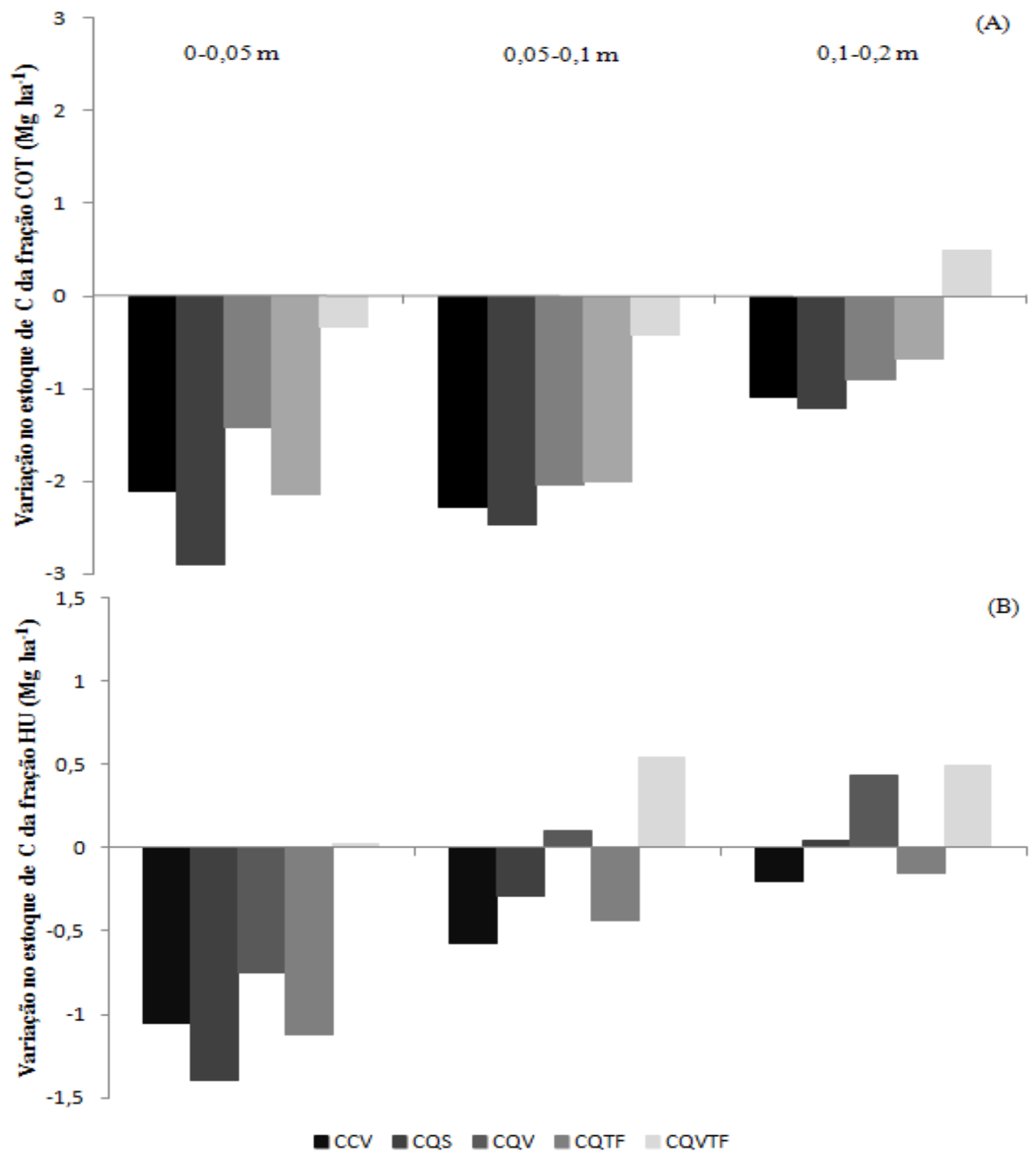

Fonte: Elaboração dos autores. 
Os menores valores para estoque de COT foram observados na área de CQS, variando de 11,04 e 22,96 $\mathrm{Mg} \mathrm{ha}^{-1}$. Ao longo dos anos, a queima do canavial, aliada a não aplicação de resíduos como a torta de filtro e vinhaça, influencia negativamente os estoques de COT. Quando o ecossistema natural é substituído por uma cultura submetida ao manejo intensivo, como a cana-de-açúcar, o estoque de COT do solo decresce substancialmente em relação ao sistema natural (CERRI, 1986). Diferentemente de quando se realiza a colheita sem a prática da queima, como observado no trabalho de Luca et al. (2008), possibilitando assim maior acúmulo de palhada sobre o solo, aumentando os teores e estoques de COT.

De maneira geral, nas áreas estudadas os estoques de carbono na fração HU foram maiores em relação aos das frações AF e AH (Tabela 3). Na profundidade de 0-0,05 m os estoques de carbono na fração HU foram maiores no solo sob VN e CQVTF. Esse comportamento sugere um possível grau avançado de humificação da matéria orgânica do solo, uma vez que a fração HU é a fração mais estável, resistente à biodegradação devido à complexação com íons metálicos e, ou argilo-húmicos estáveis (CONTEH; BLAIR, 1998; BENITES; MÁDARI; MACHADO, 2003; ASSIS et al., 2006; BARRETO et al., 2008); ou pelo fato das frações AH e AF serem menos estáveis sofrendo processos de polimerização e mineralização, com movimentação no perfil do solo, tendo sua composição diminuída (LEITE et al., 2003).

Nas áreas estudadas não ocorreu diferença nos estoques de carbono da fração $\mathrm{AH}$, porém nas profundidades de 0,05-0,10 e 0,10-0,20 m os maiores valores foram observados na área de CQVTF. Os AH são considerados marcadores do processo de humificação e refletem, como tal, tanto a condição de gênese, como de manejo do solo
(CANELLAS et al., 2003), estando relacionados a solos férteis com alto conteúdo de bases trocáveis, responsáveis pela maior CTC de origem orgânica nas camadas superficiais (BENITES; MÁDARI; MACHADO, 2003).

De maneira geral, o estoque de carbono da fração AF apresentou incremento em profundidade, possivelmente por ser a fração das substâncias húmicas de menor estabilidade com movimentação no perfil do solo acumulando-se em profundidade (LEITE et al., 2003). Os maiores estoques de AF ocorreram na área com CQVTF com valores de 3,95, 4,26 e 7,19 $\mathrm{Mg} \mathrm{ha}^{-1}$ nas profundidades de $0-0,05,0,05-0,10$ e $0,10-0,20 \mathrm{~m}$ respectivamente.

Comparando os estoques de carbono das substâncias húmicas das áreas manejadas com cana-de-açúcar em relação à VN, observou-se que tanto a fração $\mathrm{HU}$ quanto a $\mathrm{AF}$, as menores perdas ocorreram quando aplicaram-se conjuntamente torta de filtro e vinhaça (Figura 1B e Figura 2B), semelhante ao observado para estoque de COT (Figura 1A). Por outro lado, para os estoques de carbono da fração AH, além da aplicação conjunta, isoladamente torta de filtro e vinhaça também promoveram menores perdas de carbono em relação à VN (Figura 2A); corroborando em benefícios ao solo advindo do uso dos resíduos da indústria sucroalcooleira (TASSO JUNIOR et al., 2007; ZOLIN et al., 2011; CANELLAS et al., 2003). De acordo com Silva e Ribeiro (1998), o manejo do solo visando à manutenção dos resíduos vegetais, pode proporcionar maior produção de ácidos orgânicos no solo, consequentemente, melhora a fertilidade e sustentabilidade agrícola. Adicionalmente, na área com CQS, ocorreram as maiores perdas de COT, bem como os das substâncias húmicas, refletindo no declínio da fertilidade do solo com os anos de cultivo (OLIVEIRA et al., 2010). 
Figura 2. Variação do estoque de carbono na fração ácido húmico (A) e acido fúlvico (B) em função dos sistemas de manejo de colheita e aplicação de resíduos da indústria sucroalcooleira em áreas cultivadas com cana-de-açúcar, em relação à mata. CCV: cana crua com aplicação de vinhaça. CQS: cana queimada sem aplicação de resíduos. CQV: cana queimada com aplicação de vinhaça. CQTF: cana queimada com aplicação de torta de filtro. CQVTF: cana queimada com aplicação de vinhaça e torta de filtro. VN: vegetação natural.

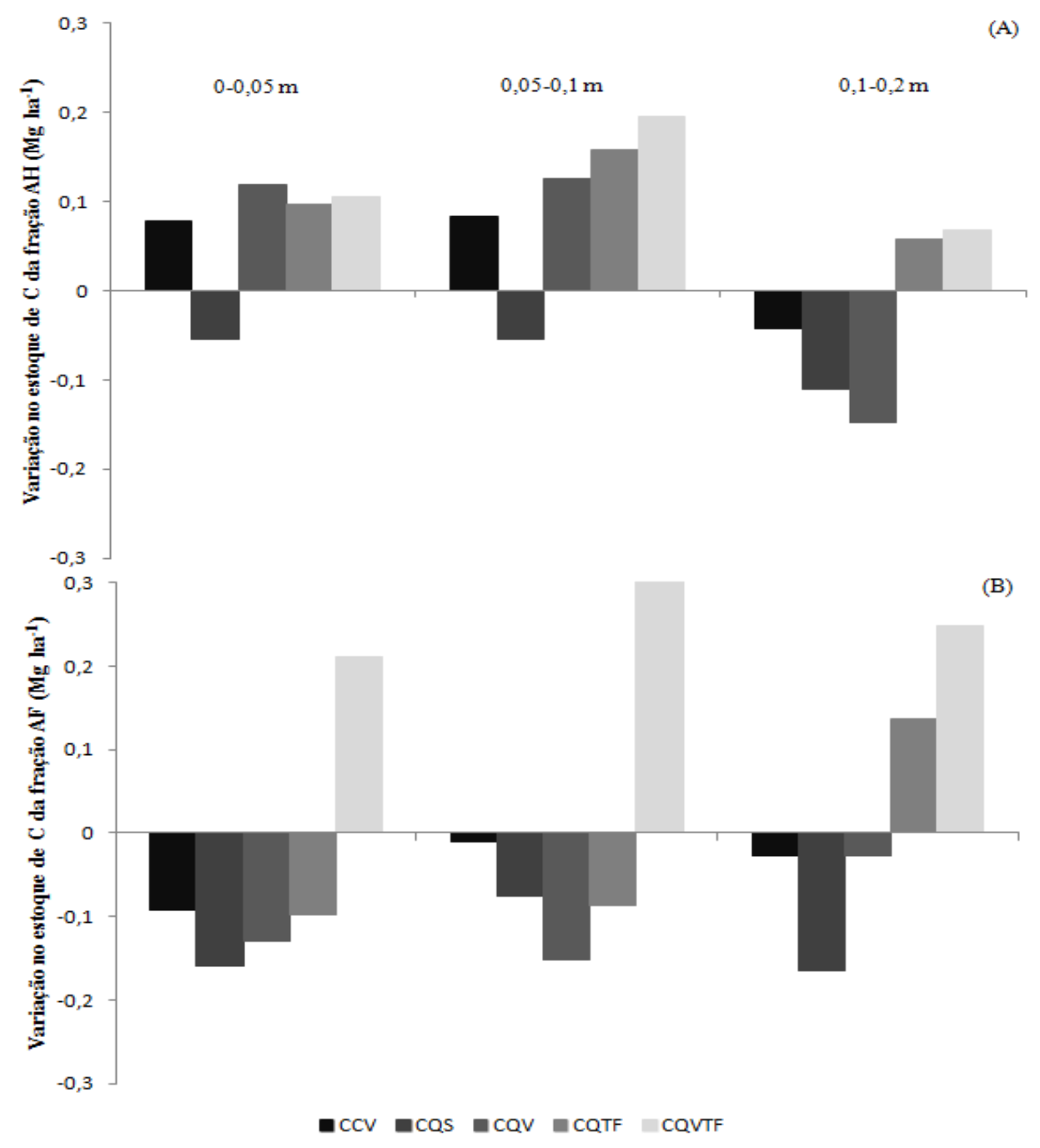

Fonte: Elaboração dos autores.

Os maiores valores da relação AH/AF ocorreram nas áreas com aplicação isolada de vinhaça e torta de filtro, principalmente nas profundidades de 0-0,05 e 0,05-0,10 m (Tabela 3). Valores desta relação superiores à unidade, indica predomínio de $\mathrm{AH}$ em relação à AF com material orgânico mais estável característico de solos férteis. Canellas et al. (2003) observaram maior relação AH/AF e aumento da fertilidade do solo em áreas de cana-de-açúcar sem a utilização da queima do canavial e aplicações sucessivas de vinhaça; sendo tal fato associado ao aumento nos teores de $\mathrm{AH}$.

Houve correlação significativa entre alguns atributos químicos e físicos do solo com o COT e carbono das frações humificadas da MOS (Tabela 4), indicando que as variações nos teores de COT e das frações humificadas proporcionam mudanças na fertilidade do solo. 
ADs apresentou correlação negativa $(\mathrm{r}=-0,69 * *)$ com os teores de COT do solo. Os teores de COT correlacionaram-se positivamente com os teores de

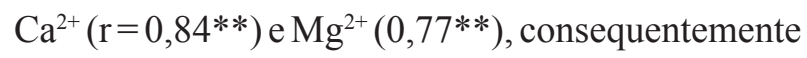
correlacionando-se positivamente com a SB (r $\left.=0,76^{* *}\right)$, CTC $\left(\mathrm{r}=0,59^{* *}\right)$ e $\mathrm{V}\left(\mathrm{r}=0,63^{* *}\right)$. A mesma tendência também foi verificada para as frações humificadas da MOS em relação à estes atributos químicos. Isso indica que os teores de COT e carbono das frações humificadas da MOS contribuem, de maneira acentuada, para o aumento nos teores destes elementos e, consequentemente, na fertilidade dos solos. Esta influência da MOS nas características químicas do solo, ocorre pela geração de cargas provenientes da MOS mais humificada, ou seja, as substâncias húmicas, por apresentarem alta superfície específica comparada às argilas do solo (ALVAREZ-PUEBLA; GOULET; GARRIDO, 2005).

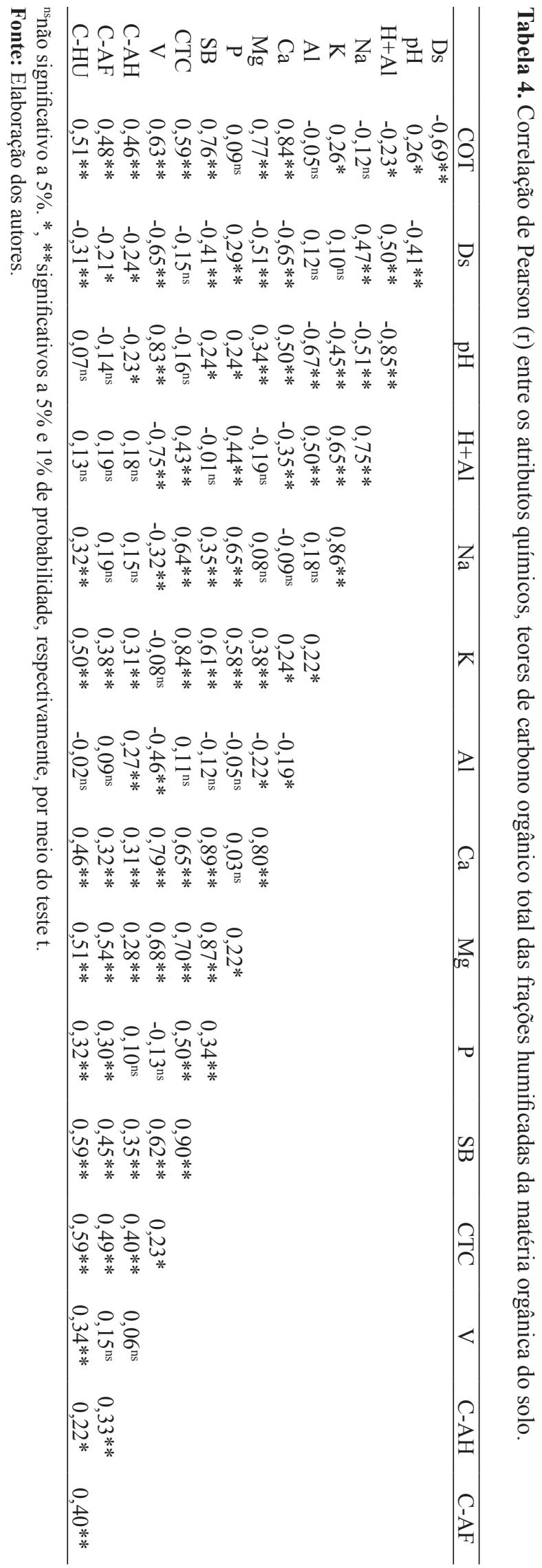




\section{Conclusões}

O solo da área de mata nativa apresentou maiores teores e estoques de carbono orgânico total e das frações humificadas da matéria orgânica do solo, bem como bons atributos relacionados à fertilidade do solo.

Dentre as áreas manejadas com cana-de-açúcar, aquela com aplicação conjunta de torta de filtro mais vinhaça, apresentou maiores estoques de carbono orgânico total e das frações humificadas, como melhoria nos atributos químicos do solo. Já o solo da área com queima sem utilização de resíduos apresentou os piores resultados dos atributos avaliados.

A manutenção do palhiço da cana-de-açúcar contribuiu para melhoria nos estoques de carbono orgânico total e das frações humificadas, com consequente melhoria nos atributos químicos do solo.

\section{Agradecimentos}

Os autores agradecem a usina LDC-SEV pela disponibilidade das áreas para a pesquisa, além do apoio logístico nas coletas de solos, a CAPES pela concessão da bolsa de Mestrado ao primeiro autor, e ao CNPq projeto "casadinho" processo 620029/2008-0, pelo apoio financeiro.

\section{Referências}

ABREU JUNIOR, C. H.; MURAOKA, T.; LAVORANTE, A. F. Exchangeable aluminum evaluation in acid soils. Scientia Agricola, Piracicaba, v. 60, n. 3, p. 543-548, 2003.

ALVAREZ-PUEBLA， L. A.; GOULET, P. J. C.; GARRIDO, J. J. Characterization of the porous structure of different humic fraction. Colloids and Surfaces A. Physicochemical and Engineering Aspects, Amsterdam, v. 256, n. 3-2, p. 129-135, 2005.

ASSIS, C. P.; JUCKSCH, I.; MENDONÇA, E. S.; NEVES, J. C. L. Carbono e nitrogênio em agregados de latossolo submetido a diferentes sistemas de uso e manejo. Pesquisa Agropecuária Brasileira, Brasília, v. 41, n. 10, p. 1541-1550, 2006.
BARRETO, A. C.; FREIRE, M. B. G. S.; NACIF, P. G. S.; ARAÚJO, Q. R.; FREIRE, F. J.; INÁCIO, E. S. B. Fracionamento químico e físico do carbono orgânico total em um solo de mata submetido a diferentes usos. Revista Brasileira de Ciência do Solo, Viçosa, MG, v. 32, n. 4, p. 1471-1478, 2008.

BEBÉ, F. V.; ROLIM, M. M.; PEDROSA, E. M. R.; SILVA, G. B.; OLIVEIRA, V. S. Avaliação de solos sob diferentes períodos de aplicação com vinhaça. Revista Brasileira de Engenharia Agrícola e Ambiental, Campina Grande, v. 13, n. 6, p. 781-787, 2009.

BENITES, V. M.; MÁDARI, B.; MACHADO, P. L. O. A. Extração e fracionamento quantitativo de substâncias húmicas do solo: um procedimento simplificado e de baixo custo. Rio de Janeiro, Embrapa, 2003. 7 p. (Comunicado técnico, 16).

BUSATO, J. G.; CANELLAS, L. P.; RUMJANEK, V. M.; VELLOSO, A. C. X. Fósforo num cambissolo cultivado com cana-de-açúcar por longo tempo. II - Análise de ácidos húmicos por rmn $31 \mathrm{p}$. Revista Brasileira de Ciência do Solo, Viçosa, MG, v. 29, n. 6, p. 945-953, 2005.

BUSATO, J. G.; CANELlaS, L. P.; VElloso, A. C. X. Fósforo num cambissolo cultivado com cana-deaçúcar por longo tempo. I - Fracionamento sequencial. Revista Brasileira de Ciência do Solo, Viçosa, MG, v. 29, n. 6, p. 935-944, 2005.

CAMARGO, F. A. O.; SANTOS, G. A.; GUERRA, J. G. M. Macromoléculas e substâncias húmicas. In: SANTOS, G. A.; CAMARGO, F. A. O. (Ed.). Fundamentos da matéria orgânica do solo. Porto Alegre: Genesis, 1999. p. 27-39.

CAMPOS, D. C. Potencialidade do sistema de colheita sem queima da cana-de-açúcar para o sequestro de carbono. 2003. Tese (Doutorado em Agronomia) - Escola Superior de Agricultura Luiz de Queiroz, Piracicaba.

CANELLAS, L. P.; VELLOSO, A. C. X.; MARCIANO, C. R.; RAMALHO, J. F. G. P.; RUMJANEK, V. M.; REZENDE, C. E.; SANTOS, G. A. Propriedades químicas de um Cambissolo cultivado com cana-deaçúcar, com preservação do palhiço e adição de vinhaça por longo tempo. Revista Brasileira de Ciência do Solo, Viçosa, v. 27, n. 5, p. 935-944, 2003.

CEDDIA, M. B.; ANJOS, L. H. C.; LIMA, E.; RAVELLI NETO, A.; SILVA, L. A. Sistemas de colheita da canade-açúcar e alterações nas propriedades físicas de um solo podzólico amarelo no Estado do Espírito Santo. Pesquisa Agropecuária Brasileira, Brasília, v. 34, n. 8, p. 1467-1473, 1999. 
CERRI, C. C. Dinâmica da matéria orgânica do solo no agroecossistema cana-de-açúcar. 1986. (Tese de Livre Docência) - Escola Superior de Agricultura Luiz de Queiroz, Piracicaba.

COMPANHIA NACIONAL DE ABASTECIMENTO CONAB. Acompanhamento da safra brasileira - Canade-açúcar, segundo levantamento, 2013/14. Compania Nacional de Abastecimento. Brasília: Conab, 2013. 17 p.

CONTEH, A.; BLAIR, G. J. The distribution and relative losses of soil organic carbon fractions in aggregate size fractions from cracking clay soils (vertisols) under cotton production. Australian Journal of Soil Research, Victoria, v. 36, n. 2, p. 257-271, 1998.

COUTINHO, L. M. O uso do fogo em pastagens naturais brasileiras. In: PUIGNAU, J. P. Utilizacion y manejo de pastizales. Montivideo: IICA-PROCISUR, Instituto Interamericano de Cooperacion para la Agricultura, 1994. p. 159-168. (Dialogo XL).

EMPRESA BRASILEIRA DE PESQUISA AGROPECUÁRIA - EMBRAPA. Centro Nacional de Pesquisa de Solos. Manual de métodos de análises de solo. 2. ed. Rio de Janeiro, 1997. 212 p.

. Sistema brasileiro de classificação de solos. 3 . ed. Brasília, 2013. 353 p.

FRAVET, P. R. F.; SOARES, R. A. B.; LANA, R. M. Q.; LANA, Â. M. Q.; KORNDÖRFER, G. H. Efeito de doses de torta de filtro e modo de aplicação sobre a produtividade e qualidade tecnológica da soqueira de cana-de-açúcar. Ciência e Agrotecnologia, Lavras, v. 34, n. 3, p. 618-624, 2010.

GAldos, M. V.; CERRI, C. C.; CERRI, C. E. P.; PAUSTIAN, K.; VAN ANTWERPEN, R. Simulation of Soil Carbon Dynamics under Sugarcane with the CENTURY Model. Soil Science Society of America Journal, Madison, v. 73, n. 3, p. 802-811, 2009.

GLÓRIA, N. A.; ORLANDO FILHO, J. Aplicação da vinhaça como fertilizante. Boletim Técnico Planalsucar, Piracicaba, v. 5, n. 1, p. 1-38, 1983.

GLÓRIA, N. A. Utilização da vinhaça. Brasil Açucareiro, Rio de Janeiro, v. 86, n. 5, p. 11-7, 1980.

GREGORICH, E. G.; BEARE, M. H.; MCKIM, U. F.; SKJEMSTAD, J. O. Chemical and biological characteristics of physically uncomplexed organic matter. Soil Science Society of America Journal, Madison, v. 70, n. 3, p. 975-985, 2006.

GUERRA, J. G. M.; SANTOS, G. A.; SILVA, L. S.; CAMARGO, F. A. O. Macromoléculas e substâncias húmicas. In: SANTOS, G. A.; SILVA, L. S.; CANELLAS, L. P.; CAMARGO, F. A. O. Fundamentos da matéria orgânica do solo: ecossistemas tropicais e subtropicais. 2. ed. Porto Alegre: Metrópole, 2008. p. 19-26.

HERINGER, I.; JACQUES, A. V. Á.; BISSANI, C. A.; TEDESCO, M. Características de um latossolo vermelho sob pastagem natural sujeita à ação prolongada do fogo e de práticas alternativas de manejo. Ciência Rural, Santa Maria, v. 32, n. 2, p. 309-314, 2002.

KRAGT, M. E.; PANNELL, D. J.; ROBERTSON, M. J.; THAMO, T. Assessing costs of soil carbon sequestration by crop-livestock farmers in Western Australia. Agricultural Systems, Amsterdam, v. 112, n. 10, p. 27-37, 2012.

LEITE, L. F. C.; MENDONÇA, E. S.; NEVES, J. C. L.; MACHADO, P. L. O. A.; GALVÃO, J. C. C. Estoques totais de carbono orgânico e seus compartimentos em argissolo sob floresta e sob milho cultivado com adubação mineral e orgânica. Revista Brasileira de Ciência do Solo, Viçosa, v. 27, n. 5, p. 821-832, 2003.

LEMOS FILHO, L. C. A.; OLIVEIRA, E. L.; FARIA, M. A.; ANDRADE, L. A. B. Variação espacial da densidade do solo e matéria orgânica em área cultivada com cana-de-açúcar (Saccharum officinarum L.). Ciência Agronômica, Fortaleza, v. 39, n. 2, p. 193-202, 2008.

LUCA, E. F.; FELLER, C.; CERRI, C. C.; BARTHÈS, B.; CHAPLOT, V.; CAMPOS, D. C.; MANECHINI, C. Avaliação de atributos físicos e estoques de carbono e nitrogênio em solos com queima e sem queima de canavial. Revista Brasileira de Ciência do Solo, Viçosa, v. 32, n. 2, p. 789-800, 2008.

MAIA, J. L. T.; RIBEIRO, M. R. Cultivo contínuo de cana-de-açúcar e modificações químicas de um Argissolo Amarelo fragipânico. Pesquisa Agropecuária Brasileira, Brasília, v. 39, n. 11, p. 1127-1132, 2004.

MARRIOTT, E. E.; WANDER, M. M. Total and labile soil organic matter in organic and conventional farming systems. Soil Science Society of America Journal, Madison, v. 70, n. 3, p. 950-959, 2006.

MENDONZA, H. N. S.; LIMA, E.; ANJOS, L. H. C.; SILVA, L. A.; CEDDIA, M. B.; ANTUNES, M. V. M. Propriedades químicas e biológicas de solos de tabuleiros cultivados com cana-de-açúcar com e sem queima da palhada. Revista Brasileira de Ciência do Solo, Viçosa, v. 24, n. 1, p. 201-207, 2000.

MIELNICZUK, J. Matéria orgânica e sustentabilidade de sistemas agrícolas. In: SANTOS, G. A.; CAMARGO, F. A. O. (Ed.). Fundamentos da matéria orgânica do solo. Porto Alegre: Genesis, 1999. p. 1-7. 
MOTTA, P. E. F.; CARVALHO FILHO, A.; KER, J. C.; PEREIRA, N. R.; CARVALHO JÚNIOR, W.; BLANCANEAUX, P. Relações solo-superfície geomórfica e evolução da paisagem em uma área do Planalto Central Brasileiro. Pesquisa Agropecuária Brasileira, Brasília, v. 37, n. 6, p. 869-878, 2002.

OLIVEIRA, E. G.; FERREIRA, M. E.; ARAÚJO, F. M. Diagnóstico do uso da terra na região centro-oeste de minas gerais, Brasil: a renovação da paisagem pela canade-açúcar e seus impactos socioambientais. Sociedade \& Natureza, Uberlândia, v. 24, n. 3, p. 545-556, 2012.

OLIVEIRA, V. S.; ROLIM, M. M.; VASCONCELOS, R. F. B.; PEDROSA, E. M. R. Distribuição de agregados e carbono orgânico em um Argissolo Amarelo distrocoeso em diferentes manejos. Revista Brasileira de Engenharia Agrícola e Ambiental, Campina Grande, v. 14, n. 9, p. 907-913, 2010.

RESCK, D. V. S.; FERREIRA, E. A. B.; FIGUEIREDO, C. C.; ZINN, Y. L. Dinâmica da matéria orgânica no Cerrado. In: SANTOS, G. A.; SILVA, L. S.; CANELLAS, L. P.; CAMARGO, F. A. O. Fundamentos da matéria orgânica do solo: ecossistemas tropicais e subtropicais. 2. ed. Porto Alegre: Metrópole, 2008. p. 359-417.

RIBEIRO, B. T.; LIMA, J. M.; CURI, N.; OLIVEIRA, G. C.; LIMA, P. L. T. Cargas superficiais da fração argila de solos influenciadas pela vinhaça e fósforo. Química Nova, São Paulo, v. 34, n. 1, p. 5-10, 2011.

ROSCOE, R.; BODDEY, R. M.; SALTON, J. C. Sistemas de manejo e matéria orgânica do solo. In:

Dinâmica da matéria orgânica do solo em sistemas conservacionistas. Dourados: EMBRAPA, 2006. p. 1742.

SANTOS, D. H.; SILVA, M. A.; TIRITAN, C. S.; FOLONI, J. S. S.; ECHER, F. R. Qualidade tecnológica da cana-de-açúcar sob adubação com torta de filtro enriquecida com fosfato solúvel. Revista Brasileira de Engenharia Agrícola e Ambiental, Campina Grande, v. 15, n. 15, p. 443-449, 2011.
SCHACHT, W. H.; STUBBENDIECK, J.; BRAGG, T. B.; SMART, A. J.; DORAN, J. W. Soil quality response of reestablished grasslands to mowing and burning. Journal Range Management, Denver, v. 49, n. 5, p. 458463, 1996.

SCHIAVO, J. A.; ROSSET, J. S.; PEREIRA, M. G.; SALTON, J. C. Índice de manejo de carbono e atributos químicos de Latossolo Vermelho sob diferentes sistemas de manejo. Pesquisa Agropecuária Brasileira, Brasília, v. 46, n. 10, p. 1332-1338, 2011.

SILVA, A. J. N.; CABEDA, M. S. V.; CARVALHO, F. G.; LIMA, J. F. W. F. Alterações físicas e químicas de um Argissolo Amarelo sob diferentes sistemas de uso e manejo. Revista Brasileira de Engenharia Agrícola e Ambiental, Campina Grande, v. 10, n. 1, p. 76-83, 2006.

SILVA, A. J. N.; RIBEIRO, M. R. Caracterização de um Latossolo Amarelo sob cultivo contínuo de cana-deaçúcar no Estado de Alagoas: propriedades químicas. Revista Brasileira de Ciência do Solo, Viçosa, v. 22, n. 2, p. 291-299, 1998.

TASSO JÚNIOR, L. C.; MARQUES, M. O.; FRANCO, A.; NOGUEIRA, G. A.; NOBILE, F. O.; CAMILOTTI, F.; SILVA, A. R. Produtividade e qualidade de cana-deaçúcar cultivada em solo tratado com lodo de esgoto, vinhaça e adubos minerais. Engenharia Agrícola, Jaboticabal, v. 27, n. 1, p. 276-283, 2007.

VICENTE, T. F. S.; PEDROSA, E. M. R.; ROLIM, M. M.; OLIVEIRA, V. S.; OLIVEIRA, A. K. S.; SOUZA, A. M. P. L. Relações de atributos do solo e estabilidade de agregados em canaviais com e sem vinhaça. Revista Brasileira de Engenharia Agrícola e Ambiental, Campina Grande, v. 16, n. 11, p. 1215-1222, 2012.

YEOMANS, A.; BREMNER, J. M. A rapid and precise method for routine determination of organic carbon in soil. Communication Soil Science Plant Analysis, Philadelphia, v. 19, n. 13, p. 1467-1476, 1988.

ZOLIN, C.A.; PAULINO, J.; BERTONHA,A.; FREITAS, P. S. L.; FOLEGATTI, M. V. Estudo exploratório do uso da vinhaça ao longo do tempo. I. Características do solo. Revista Brasileira de Engenharia Agrícola e Ambiental, Campina Grande, v. 15, n. 1, p. 22-28, 2011. 